\title{
Desempenho em nomeação de figuras de crianças com dislexia
}

\section{Performance in naming figures of children with dyslexia}

DOI: $10.46919 / \operatorname{archv2n1-006~}$

Recebimento dos originais: 30/10/2020

Aceitação para publicação: 23/12/2020

\section{Débora Leitão Gomes}

Especialista em Neuropsicologia - CFP

Instituição de atuação atual: Instituto de Neurociência de Brasília INCB

Endereço completo: SGAS, 610, Bloco 2 - salas229/230/231 - Asa Sul - Brasília

E-mail: Deborah_lgomes@hotmail.com

\section{Bruna Vaz de Melo e Freitas}

Especialista em Terapia comportamental - IWP

Instituição de atuação atual: Consultório Particular

Endereço completo:10a Avenida, N. ${ }^{\circ}$ 100, Qd. 67B, Lt.03 - CEP74645-040

E-mail: brunavfreitas@gmail.com

\section{Sheila Corrêa Coutinho Carvalho}

Especialista em Neuropsicologia

Instituição de atuação atual: PUC-GOIÁS

Endereço completo: avenida Universitária - Setor Universitário - Goiânia - Goiás CEP 74175-120

E-mail: sheilacorcarvalho@ hotmail.com

Ludmilla Gomes Rufino Mendes

Graduação em Psicologia

Instituição de atuação atual: PUC-GOIÁS

Endereço completo: avenida Universitária - Setor Universitário - Goiânia - Goiás CEP 74175-120

E-mail: rufinopsicologia@hotmail.com

\section{Ariane Cristina Ramello Carvalho}

Doutora em Distúrbios do Desenvolvimento

Instituição de atuação atual: Universidade Presbiteriana Mackenzie

Endereço completo: Rua Sergipe, 401, conjunto 607, Higienópolis - São Paulo

E-mail: Ariane.ramello@gmail.com

\section{Weber Martins}

Doutorado em Dphil in Eletronics Artificial Neural Networks -University of York- Inglaterra. Instituição de atuação atual: PUC-GOIÁS/UFG

Endereço completo: avenida Universitária, 1488 - Setor Universitário - Goiânia - Goiás - CEP: 74605-

010

E-mail: webermartins@gmail.com 


\title{
Sandra de Fátima Barboza Ferreira
}

Doutora em Psicologia - PUC-GOIÁS

Instituição de atuação atual: Universidade Federal de Goiás - UFG

Endereço completo: Rua 235 - Setor Universitário - Goiânia - Goiás - CEP 74605-050

E-mail: sandrabarbozaf@gmail.com

\section{RESUMO}

A Dislexia é definida como uma defasagem na habilidade de leitura e escrita em relação à capacidade de compreensão e inteligência geral, e suposta educação formal de qualidade. Além dessas dificuldades, há concordância entre autores em relação a existência de um déficit metalinguístico envolvendo a dificuldade de nomeação rápida, a falta de consciência metafonológica e o déficit de memória de trabalho e dificuldade de sequencialiazação, fatores que dificultam a aquisição da leitura e da escrita. O objetivo do trabalho é comparar o desempenho em nomeação de figuras de crianças sem queixas escolares e crianças com Dislexia. Participaram da pesquisa 271 alunos do grupo controle sem histórico de repetência ou queixa escolar e 16 do grupo clínico, na faixa etária de 8 a 12 anos, com diagnóstico formalizado de dislexia. Utilizou-se o Teste de Nomeação de Figuras e realizou-se estatística descritiva (média) e inferencial (MannWhitney). Os resultados sugerem que os disléxicos de fato têm dificuldade ao nomear figuras corroborando dados da literatura. $\mathrm{O}$ estudo possibilitou ainda afirmar que algumas figuras são mais consensualmente nomeadas e que há itens do teste de figuras que devem ser melhor estudados. Estudos futuros poderão ainda discutir qualitativamente a natureza das dificuldades encontradas no grupo com dislexia. Estudos relacionados à déficits de categoria de figuras distintas devem ser implementados. $\mathrm{O}$ estudo aponta ainda para a possibilidade de, conhecidas as dificuldades de nomeação encontradas no grupo com dislexia, implementar projeto de reabilitação que envolva esta habilidade, bem como estudo de rastreio que possa, a partir da inabilidade de nomear figuras, oferecer suporte adicional com vistas a minimizar o impacto destas dificuldades no processo de aquisição de leitura e escrita.

Palavras-chave: Dislexia, Nomeação, Disnomia, Anomia, Teste de nomeação.

\begin{abstract}
Dyslexia is defined as a mismatch in reading and writing ability from general intelligence and comprehension ability, and supposedly quality formal education. In addition to these difficulties, there is agreement among authors regarding the existence of a metalinguistic deficit involving the difficulty of rapid appointment, the lack of metaphonological awareness, and the deficit of work memory and difficulty of sequentialization, factors that make it difficult to acquire reading and writing. The objective of the work is to compare the performance in naming figures of children without school complaints and children with dyslexia. In the survey, 271 students from the control group with no history of repetition or school complaints and 16 from the clinical group, aged 8 to 12 years, with a formalized diagnosis of dyslexia, participated. The Figures Nomination Test was used and descriptive (average) and inferential (MannWhitney) statistics were performed. The results suggest that dyslexics actually have difficulty naming figures corroborating data from the literature. The study also made it possible to affirm that some figures are more consensually named and that there are items of the figure test that should be better studied. Future studies may also discuss qualitatively the nature of the difficulties encountered in the group with dyslexia. Studies related to deficits of distinct figure category should be implemented. The study also points to the possibility of, knowing the naming difficulties encountered in the group with dyslexia, implementing a rehabilitation project that involves this ability, as well as a screening study that may, from the inability to name figures, offer additional support in order to minimize the impact of these difficulties on the reading and writing acquisition process.
\end{abstract}

Keywords: Dyslexia, Appointment, Dysnomy, Anomy, Nominating test. 


\section{INTRODUÇÃO}

A Dislexia (ou Transtorno de Leitura e Escrita) é definida como uma defasagem na habilidade de leitura e escrita em relação à capacidade de compreensão e inteligência geral, além de suposta educação formal de qualidade. Consensualmente é possível identificar déficits cognitivo-linguísticos (VELUTINO, 2004; CAPELlINI, PADULA, SANTOS, LOURENCETI, CARRENHO \& RIBEIRO, 2007; BERNINGER, 2008; CAPELLINI \& GERMANO, 2016; REMINEN \& NARVARRA, 2020).

A Classificação Internacional de Doenças - CID-10 (OMS,1993) e o Manual Diagnóstico e Estatístico de Transtornos Mentais - DSM-5 (APA, 2014) destacam que se trata de um comprometimento específico no desenvolvimento das habilidades de leitura, o qual não é unicamente justificado por déficit cognitivo, problemas sensoriais ou escolaridade inadequada. As dificuldades manifestam-se tanto por problemas de decodificação como de codificação (leitura fluente e precisa e ortografia) e abrangem aspectos relacionados á precisão, velocidade e compreensão. Estas dificuldades iniciam-se nos anos escolares, mas podem acompanhar o indivíduo por toda vida, trazendo prejuízo funcional persistente, marcadamente no ambiente acadêmico estendendo-se a vida profissional no tocante ao uso da expressão escrita.

Quanto aos aspectos epidemiológicos as pesquisas relacionadas à dislexia não apresentam consenso. Porém, estima-se aproximadamente 4 a $10 \%$ da população mundial. No Brasil calcula-se que cerca de 5 a 10\% da população tenha este transtorno, conforme Nico, Bianchini e Barreira (1998) e Ciasca, Lima e Ribeiro (2016). Pondera-se que essa variabilidade e alta prevalência pode estar relacionada com a ausência de um diagnóstico diferencial com outras dificuldades de aprendizagem. Em estudo recente de revisão Reminen e Narvarra (2020) encontraram em torno de 7\% de incidência para a população mundial.

Quanto á etiologia, do ponto de vista neurológico, a dislexia é considerada uma disfunção do Sistema Nervoso Central que compromete a aquisição e o desenvolvimento das habilidades escolares (ARTIGAS-PALLARÉS, 2009; DEHAENE, 2012). A dislexia é hereditária. Por outro lado, Remien e Narvarra (2020) destacam que a alfabetização em casa e a qualidade de ensino impactam fortemente a capacidade de leitura da criança. Desse modo, além de genético pode-se considerar também que o transtorno é epigenético. Estudos com gêmeos mostraram que as dificuldades de leitura são altamente hereditárias e estudos genéticos recentes encontraram vários pequenos genes que afetam diretamente a migração de neurônios e a morfogênese cortical influenciando o mal processamento da habilidade de leitura (REMIEN \& NAVARRA, 2020).

Alterações em áreas encefálicas no corpo caloso, presença de ectopias e simetria dos hemisférios na sua porção temporal foram identificadas em estudos de Galaburda na década de 80 (JURADO, 2006). Além disso, há evidências de um componente hereditário associado a diversos genes candidatos restritos a uma posição de risco específico em diferentes cromossomos. Os genes CYP19A1 e DYX1C1 podem ser ligados a aspectos ambientais relacionados a dislexia (VARSHNEY E NALVARTE, 2017). 
Pesquisas recentes têm sugerido que os efeitos cromossômicos e de hormônios sexuais, especialmente a testosterona (JURADO, 2006) podem exercer papéis fundamentais durante o desenvolvimento de forma que, até mesmo uma pequena desregulação neste período pode afetar meninos e meninas de formas diferentes. Sendo assim, meninos tendem a ser mais afetados por transtornos do espectro do autismo, transtorno de déficit de atenção e hiperatividade e dislexia, enquanto meninas são mais suscetíveis a transtornos de ansiedade e depressão (VARSHNEY E NALVARTE, 2017).

Ao longo do estudo dessa condição nosográfica, a Dislexia recebeu algumas classificações. Ramello, Fernandes e Ferreira (2012); Ciasca, Lima e Ribeiro (2016) e Capellini e Germano (2016), apoiados na tipificação de Boder (1973), destacam os três tipos de dislexia: a) disfonética, caracterizada por dificuldades na leitura oral de palavras pouco familiares, na conversão grafema-fonema, podendo ocorrer por possível disfunção no lobo temporal; b) diseidética, caracterizada por dificuldade no processamento visual, na qual a criança lê por meio de um processo elaborado de análise e síntese fonética e possível disfunção no lobo occipital; c) mista, caracterizada por dificuldades dos dois tipos anteriores, podendo ser associada à disfunção dos lobos pré-frontal, occipital e temporal. (RAMELLO, FERNANDES, FERREIRA, 2012; CIASCA, LIMA, RIBEIRO, 2016; CAPELLINI \& GERMANO, 2016).

Assim, pode-se dizer que tal transtorno diz respeito a dificuldades singulares apresentadas pelo indivíduo à apropriação e uso estável e generalizado da comunicação escrita, podendo coexistir com dificuldade de linguagem oral, nomeação, cálculo, atenção, memória e integração perceptivo-motora (ALVARES, ZAIDAN, 2000; CAPELLINI \& GERMANO, 2016; REMIEN \& NAVARRO, 2020).

Além das dificuldades descritas acima, existe concordância entre autores (ETCHPAREBORDA, 2003; CAPELLINI, SALGADO, 2003; HOUT, ESTIENNE, 2001) em relação a existência de um déficit metalinguístico na Dislexia envolvendo a dificuldade de nomeação, a falta de consciência metafonológica e o déficit de memória de trabalho e dificuldade de sequencialização, fatores que dificultam a aquisição da leitura e da escrita. Neste sentido, um estudo realizado por Oliveira e colaboradores (2014), demonstrou que crianças com dislexia apresentam dificuldade no reconhecimento da palavra, especialmente no uso da estratégia ortográfica durante a leitura, bem como, apresentam comprometimento na velocidade de processamento.

Bueno, Lukasova, Macedo, Piza e Toledo (2009) e Capellini e Germano (2016), relatam que a deficiência no processamento fonológico influencia em outras tarefas como a nomeação de figuras. A nomeação exige a ativação de representações fonológicas; por isso, leitores disléxicos também apresentam desempenho deficiente em nomeação. Em consonância com essa afirmação Shaywitz, (2006) acrescenta que, os erros dos disléxicos ao nomear objetos ou figuras advêm das confusões que fazem entre os sons das palavras. Assim, mediante a necessidade de evocar respostas rápidas diante de nomeação por confronto visual, o disléxico demonstrará desempenho inferior ao esperado. 
A capacidade de nomear em tarefas de confronto visual ou de figuras é um processo que envolve também a representação mental da imagem, obtido através da discriminação visual que envolve os aspectos de diferenciação figura/fundo, síntese visual, percepção, associação de cores, localização de pontos no espaço, julgamento de direção e distância, orientação topográfica, percepção de profundidade e de distância, que permite conhecer os objetos, a partir de figuras propostas, de acordo com o sistema semântico (HILLIS, 2001 \& SCHEUER ET AL., 2004 APUD ARAÚJO, GRECO, MANSUR, RADANOVIC \& TAQUEMORI, 2006; FERREIRA, NALINI \& PASQUALI (2011) CAPELLINI \& GERMANO, 2020; FERREIRA, PASQUALI \& NALINI, 2020).

O déficit encontrado na nomeação de figuras em crianças com Transtorno da Leitura pode ser explicado pelo prejuízo no processamento fonológico, considerado a causa principal das alterações na aquisição e no desenvolvimento da leitura. O prejuízo no processamento fonológico pode dificultar a construção da representação mental da estrutura fonológica e do mecanismo de acesso a esta informação (GOSWAMI, 2001; GVION, FRIEDMANN, 2016; CAPELLINI \& GERMANO, 2016), interferindo na recuperação dos nomes das figuras.

Conforme destacam Ferreira, Nalini e Pasquali (2011) e Ferreira, Pasquali \& Nalini (2020) a dificuldade de nomeação ou disnomia é um preditor importante de dificuldades na aquisição da expressão oral e escrita e constitui um dos mais importantes preditores de deterioração da linguagem marcadamente presente em todos os tipos de afasia.

Capellini, Ferreira, Salgado e Ciasca (2007) demonstram a importância da nomeação rápida para o processo de aquisição da leitura. Em suas pesquisas, encontraram resultados demonstrando que crianças disléxicas apresentam maior dificuldade em tarefas de nomeação rápida, quando comparadas com crianças com Transtorno de Déficit de atenção/hiperatividade (TDA/H) e com crianças que leem de acordo com o esperado para a idade e grau de escolaridade, concluindo assim que a habilidade de nomeação rápida pode ser considerada um pré-requisito para o desempenho em leitura.

O objetivo desse estudo foi comparar o desempenho em nomeação de figuras de crianças sem queixas escolares e crianças com diagnóstico formalizado de Dislexia e analisar se apresentam desempenho inferior no teste de nomeação.

\section{METODOLOGIA}

Participantes: Participaram desta pesquisa 287 escolares, com idade entre 8 e 12 anos, oriundos de escolas públicas e particulares do Estado de Goiás. O projeto de pesquisa foi aprovado pelo Comitê de Ética e Pesquisa, sob o protocolo (01108712.6.0000.0037). Dessa amostra, 271 crianças compuseram o Grupo Controle-GC (sem histórico ou queixas de dificuldades escolares) e 16 o grupo clínico -GCl (com diagnóstico formalizado de Dislexia). Da amostra total 151 pertenciam às escolas particulares, dos quais 
10 com diagnóstico formalizado de dislexia, enquanto 136 pertenciam à escola pública, seis deles com diagnóstico formalizado de Dislexia).

Instrumentos: a) termo de consentimento livre e esclarecido - TCLE, preenchido e assinado pelos responsáveis pela criança; b) Ficha de levantamento sociodemográfico contendo dados básicos de identificação; c) Teste de Nomeação de Figuras - versão experimental (FERREIRA, NALINI \& PASQUALI, 2011) composta por um conjunto de 78 figuras numeradas (Os estímulos foram cuidadosamente testados e divididos abrangendo categorias semânticas, fonéticas, extensão dos nomes e complexidade visual; d) Protocolo da folha de resposta contendo espaço para o registro dos nomes indicados pelos participantes, seguido de pista semântica e fonética e campo específico para registro do somatório de respostas corretas, erros e observações qualitativas relativas à circunlóquios/confabulações visuais/neologismos (ANEXO 1).

Procedimentos: Para a realização da coleta de dados, informou-se devidamente às instituições sobre a natureza e objetivo da pesquisa. Procedeu-se a assinatura do TCLE pela direção das escolas, bem como pelos responsáveis pelas crianças. Para o grupo controle considerou-se como critérios de inclusão ter entre 08 e 12 anos de idade, estar cursando a série correspondente ao seu grupo etário e não apresentar queixa de dificuldade de aprendizagem. Como critério de exclusão foram considerados alunos com histórico de repetência e laudo de transtorno de aprendizagem. Realizou-se a coleta de dados em sessão única e ambiente apropriado, nos turnos, matutino e vespertino, sendo gastos em média 10 minutos por sessão. Encaminhouse o levantamento sócio-demográfico para a residência dos participantes, para o preenchimento pelo responsável. Realizou-se a aplicação do Teste de Nomeação de figuras (FERREIRA, NALINI \& PASQUALI, 2011; FERREIRA, NALINI \& PASQUALI, 2020) versão experimental composta de 78 figuras: Os resultados foram registrados em folha de resposta apropriada (ANEXO 1).

A população clínica foi acessada a partir da clientela da clínica escola de uma instituição universitária e de um serviço especializado de atendimento a crianças da rede municipal de ensino. Considerou-se como critério de inclusão ter entre 8 e 12 anos de idade, ter diagnóstico de dislexia formalizado em laudo multidisciplinar. Foi realizado o contato com os responsáveis e, mediante adesão, agendada sessão única de levantamento de dados sociodemográficos e aplicação da versão experimental do Teste de Nomeação de figuras (FERREIRA, NALINI \& PASQUALI, 2011; FERREIRA, NALINI \& PASQUALI, 2020). As respostas foram registradas no protocolo de registro. (ANEXO 1)

Para análise dos resultados procedeu-se então a somatória de acertos de respostas espontâneas e respostas com pistas semânticas. Os acertos após pista fonética não foram computados em consonância com a teoria pertinente ao teste de nomeação (FERREIRA, NALINI \& PASQUALI, 2011; FERREIRA, PASQUALI \& NALINI, 2020). Registrou-se o resultado total obtido pelos participantes no banco de dados do Statiscal Package for Social Science - SPSS - Versão 18.0. 


\section{RESULTADOS}

As tabelas 1 e 2 apresentam a distribuição da amostra por tipo de grupo (controle e clínico) e por gênero. Além de critérios estatísticos relativos ao cálculo amostral primou-se por obedecer ainda ao critério de proporcionalidade para o transtorno preconizado pelo DSM-5 (2014) e dados de prevalência na população brasileira (em torno de 5\%). Ambos os grupos apresentaram idade média de 10 anos. Quanto ao gênero, observou-se a predominância feminina em ambos os grupos, porém destaca-se a pequena diferença, em valores absolutos, entre os resultados relacionados ao gênero e a dislexia, indicando que nesta amostra a prevalência quanto ao gênero não foi estatisticamente significativa.

Tabela 1. Distribuição da Amostra por Tipo de Grupo

\begin{tabular}{ccc}
\hline Grupo & n & \% \\
\hline Controle & 271 & 94,4 \\
Dislexia & 16 & 5,6 \\
Total & 287 & 100,0 \\
\hline
\end{tabular}

Tabela2 - Distribuição de participantes em relação a gênero e grupo

\begin{tabular}{|c|c|c|c|}
\hline $\begin{array}{l}\text { Gênero do } \\
\text { participante }\end{array}$ & & & Total \\
\hline Masculino & 120 & 7 & 127 \\
\hline Feminino & 151 & 9 & 160 \\
\hline Total & 271 & 16 & 287 \\
\hline
\end{tabular}

A Tabela 3 apresenta o Teste de aderência Kolmogorov - Smirnov para verificação de normalidade. Devido à falta de normalidade da referida variável $(\mathrm{p}<0,001)$ nos dois grupos, utilizou-se o teste nãoparamétrico de Mann-Whitney, conforme mostrado na Tabela 4, para comparar a posição média (ranking médio) dos grupos e avaliar a significância das diferenças entre os dois grupos independentes.

Tabela 3.Teste de comprovação de normalidade de cada uma das variáveis

\begin{tabular}{ccccc}
\hline Grupo & n & Média & Desvio Padrão & P \\
\hline Controle & 271 & 73,06 & 3,63 & $<0,001$ \\
Dislexia & 16 & 60,19 & 8,38 & 0,477 \\
\hline
\end{tabular}

Teste de aderência Kolmogorov-Smirnov para de uma variável para comprovação ou não de normalidade.

Tabela 4. Resultado do Teste de Mann-Whitney demonstrando a posição média de desempenho nos dois grupos no Teste de Nomeação

\begin{tabular}{cccc}
\hline & Grupo & $\mathrm{N}$ & Posição Média \\
\hline \multirow{2}{*}{ Pontos no Teste } & Controle & 271 & 150,44 \\
de Nomeação & Experimental & 16 & 35,00 \\
& Total & 287 & \\
& & Mann-Whitney & 424,00 \\
& & Significância Bicaudal & $<0,001$ \\
\hline
\end{tabular}

A Tabela 5 apresenta a média de pontos e o desvio-padrão obtidos pelos grupos clínicos e controle O teste de comparação entre médias (Mann Whitney), evidenciando que as diferenças encontradas entres 
os dois grupos foram estatisticamente significativas. Este dado confirma a hipótese levantada sobre a disparidade de tal habilidade dentre os grupos pesquisados.

Tabela 5 - Média, DP e Intervalo de Confiança da Média em cada grupo.

\begin{tabular}{lcccc}
\hline \multirow{2}{*}{ Grupo } & \multirow{2}{*}{ Média } & DP & \multicolumn{2}{c}{ IC (95\%) } \\
\cline { 3 - 5 } & 73,06 & 3,63 & 72,63 & 73,50 \\
Controle & 60,19 & 8,38 & 55,72 & 64,66 \\
Dislexia & $\mathrm{p}<0,001-$ Teste: U Mann Whitney
\end{tabular}

\section{DISCUSSÃO}

Através desse trabalho buscou-se comparar o desempenho em nomeação de crianças sem queixas escolares (GC) e crianças com Dislexia (GCL). Os resultados quanto às respostas de nomeação estão de acordo com os autores que encontraram discrepância nas respostas de nomeação em crianças sem queixas escolares e crianças com dislexia. O déficit encontrado na nomeação de figuras em crianças com Transtorno da Leitura pode ser explicado pelo prejuízo no processamento fonológico, considerado a causa principal das alterações na aquisição e no desenvolvimento da leitura. O prejuízo no processamento fonológico pode dificultar a construção da representação mental da estrutura fonológica e do mecanismo de acesso a esta informação (GOSWAMI, 2001; GVION, FRIEDMANN, 2016; GOSWAMI, CAPELLINI E GERMANO, 2016; FERREIRA, NALINI \& PASQUALI, 2011; FERREIRA, PASQUALI \& NALINI, 2020), interferindo na recuperação dos nomes das figuras.

As diferenças entre os grupos mostraram-se evidentes. O estudo quantitativo possibilitou confirmar a hipótese levantada quanto às diferenças intergrupos e os resultados corroboram dados da literatura: Bueno, Lukasova, Macedo, Piza \& Toledo (2009) e Capellini e Germano (2016) relatam que a deficiência no processamento fonológico influencia em outras tarefas como a nomeação de figuras. A nomeação exige a ativação de representações fonológicas; por isso, leitores disléxicos também apresentam desempenho deficiente em nomeação. Em consonância com essa afirmação, Shaywitz, (2006) e Salles e Corso (2016) acrescentam que, os erros dos disléxicos, ao nomearem objetos ou figuras, advêm das confusões que fazem entre os sons das palavras. Assim, mediante a necessidade de evocar respostas rápidas diante de nomeação por confronto visual ou por apresentação de figuras, o disléxico demonstra desempenho inferior ao esperado. Os resultados da pesquisa confirmam a hipótese do presente estudo, ou seja, existe uma dificuldade na habilidade de nomeação em crianças com Dislexia comparadas a crianças sem queixas escolares. Testar essa função pode aumentar segurança na produção diagnóstico da dislexia. O conhecimento da relação das dificuldades de nomeação com a dislexia pode nortear projetos terapêuticos e educacionais de alfabetização e enfrentamento das dificuldades e transtornos de aprendizagem. É útil 
considerar o treino dessa habilidade e incentivar que tarefas e atividades de geração semântica e fonética sejam intencional e ostensivamente realizadas como requisito para o aprendizado da leitura e escrita.

Estudos futuros poderão ainda discutir qualitativamente a natureza das dificuldades encontradas no grupo com dislexia. Estudos relacionados à déficits de categoria de figuras distintas também são sugeridos. 


\section{REFERÊNCIAS}

ALVARES, A.M.M.A; ZAIDAN, E. Processamento auditivo central e dislexia: novas abordagens em habilitação. In_ A.B.D. em Dislexia Cérebro e Cognição e Ap. SP: Frontiers Editorial, 2000.

ARTIGAS-PALLARÉS J. Dislexia: enfermedad, transtorno o algo distinto. Rev Neurol; 42(Supl 2): S63-S69, 2009.

BERNINGER, V.W., NIELSEN, K.H., ABBOTT RD, WIJSMAN E, RSKIND W. Writing problems in development dyslexia: under-recognized and under-treated. Journal of School Psychology; 46:2-21, 2008.

BUENO, O.F.A., LUKASOVA, K., MACEDO, E.C., PIZA, C.M.J.T. Perspectivas Atuais a Cerca da Dislexia do Desenvolvimento: Da Avaliação ao Diagnóstico. In_ MONTIEL, JOSÉ M., CAPOVILLA, FERNANDO C. Atualizações em Transtornos do desenvolvimento. São Paulo: Artes Médicas, 2009.

CAPELINI S.A., FERREIRA T.L, SALGADO C.A, CIASCA S.M. Desempenho de escolares bons leitores, com dislexia e com transtorno de déficit de atenção e hiperatividade em nomeação automática rápida. Revista Sociedade Brasileira de Fonoaudiologia. 12(2): 2007, 114-9, 2003.

CAPELLINI S.A., PADULA N, SANTOS L, LOURENCETI MD, CARRENHO R, RIBEIRO L. Desempenho em consciência fonológica, memória operacional, leitura e escrita na dislexia familial. Pró-Fono R. Atual. Cient.; 19(4): 374-80, 2007.

CAPELLINI, S.A. ET AL. Desempenho de escolares bons leitores, com dislexia e com transtorno de déficit de atenção e hiperatividade em nomeação automática rápida. Revista Sociedade Brasileira de Fonoaudiologia, São Paulo, v. 12, n. 2, p. 114-119, maio, 2007.

CAPELLINI, S. A.; MOUSINHO, R. Dislexia do desenvolvimento. In_SANTOS, F. H.; ANDRADE, V. M.; BUENO, O. F. A. Neuropsicologia hoje. Porto Alegre: Artmed, 2015.

CAPELLINI, S. A. \& GERMANO, G. D. Dislexia do desenvolvimento: contribuições das teorias para o diagnóstico e a intervenção. Em: SALLES, J.F., HAASE, V.G. \& MALLOY-DINIZ, L. Neuropsicologia do desenvolvimento. Porto Alegre: ARTMED/SBNp, 2016.

CASELLA, E.B. Dislexia do desenvolvimento. In_ MIOTTO, E. C.; LUCIA, M. C. S.; SCAFF, M. (Orgs.). Neuropsicologia clínica. Rio de Janeiro: Roca, 2017.

CIASCA, S.M.; LIMA, R.F., RIBEIRO, M.V.L.M. Avaliação e Manejo Neuropsicológico da Dislexia. In_ ROTTA, N. T.; OHLMEILER, L.; et. al. Transtornos de Aprendizagem. Porto Alegre, Artmed, 2016.

CORSO, H.V.; SALLES, J. Preditores Neuropsicológicos da Leitura. Em: J. S. FUMAGALLI; V.G. HAASE; L. MALLOY-DINIZ. (Org.) Neuropsicologia do Desenvolvimento. Porto Alegre: ARTMED/SBNp, 2016.

DEHAENE, S. Os neurônios da leitura. Como a ciência explica nossa capacidade de ler. Porto Alegre: Penso, 2012.

ETCHPAREBORDA M.C. La intervencion em lós transtornos disléxicos: entrenamiento de La Consciência fonológica. Suplementos de Revista de Neurologia, 1 (36) 2003, 13-19. Capellini e Salgado, 2003.

FERREIRA, S.B.F, NALINI, L.E.G \& PASQUALI, L. Teste de Nomeação de Figuras. Versão experimental [estudo não publicado]. Goiânia, 2011. 
FERREIRA, S.B.F., PASQUALI, L., NALINI, L. Teste de Nomeação para crianças - TNF-C. Bases epistemológicas, empíricas e psicométricas. Mauritius: Novas edições acadêmicas, 2020.

GOSWAMI. U. Early phonological development ant the acquisition of literacy. Em: Neuman SB E Dickinson DK, editors. Handbook of early literacy research. New York: The Guilford Press, 2001.

GVION, A.; FRIEDMANN, N. A Principled Relation between Reading and Naming in Acquired and Developmental Anomia: Surface Dyslexia Following Impairment in the Phonological Output Lexicon. Journal Journal Frontiers in Psycholog, v.7, p. 1 - 16, 2017.

JURADO, M.A. Disfasias, Dislexias, Disgrafias e Discalculias. Em: PLAJA, C.J., RABASSA, O.B. \& SERRAT, M.M. Neuropsicologia da Linguagem. Funcionamento normal e patológico/Reabilitação.São Paulo: Santos, 2006.

HOUT A.V, ESTIENNE F. Dislexias: descrição, avaliação, explicação e tratamento; Porto Alergre: Artmed, 2001.

NICO, A; BIANCHINI, M; BARREIRA, M. "Estudo Comparativo de um Grupo de Dislexicos da Associação Brasileira de Dislexia" - Conferência - III Simpósio Internacional de Dislexia. São Paulo, 1998.

OLIVEIRA, D. G.; SILVA, P. B.; DIAS, N. et al. Reading component skills in dyslexia: word recognition, comprehension and processing speed. Journal Frontiers in Psycholog, v.5, p. 1 - 6, 2014.

ORGANIZAÇÃO MUNDIAL DE SAÚDE - OMS. Classificação dos Transtornos Mentais e de Comportamento - CID-10: Descrições Clínicas e Diretrizes Diagnósticas. Porto Alegre: Artmed, 1993, Reimp 2008.

RAMELLO, A.C., FERNANDES, M. \& FERREIRA, S. F. B. Dislexia: avaliação neuropsicológica. Em: CAIXETA, L. \& FERREIRA, S.F.B. Manual de Neuropsicologia. Dos princípios à reabilitação. São Paulo: Atheneu, 2012.

REMIEN K, MARWAHA R. Dyslexia. In: StatPearls [Internet]. Treasure Island (FL): StatPearls Publishing; 2020 Jan-. PMID: 32491600. https://pubmed.ncbi.nlm.nih.gov/32491600/

SALLES, J.F. \& CORSO, H. V. Preditores neuropsicológicos da leitura. Em SALLES, J.F.; HAASE, V. G. \& MALLOY-DINIZ, L. Neuropsicologia do desenvolvimento. Porto alegre: ARTMED/SBNp. 2016

SHAYWITZ, S. Entendendo a Dislexia - Um Novo e Completo Programa para Todos os Níveis de Problema de Leitura. Porto Alegre: Artmed, 2006.

VÁGVÖLGYI, R.; COLDEA, A.; DRESLER, T.; SCHRADER, J.; NUERK, H.-C. A Review about Functional Illiteracy: Definition, Cognitive, Linguistic, and Numerical Aspects. Frontiers in Psychology, 7, 2016. http://doi.org/10.3389/fpsyg.2016.01617

VARSHNEY, M.; NALVARTE, I. Genes, Gender, Environment, and Novel Functions of Estrogen Receptor Beta in the Susceptibility to Neurodevelopmental Disorders. Brain Sciences, 7(3), 24, 2017 http://doi.org/10.3390/brainsci7030024

VELLUTINO F.R, FLETCHER J.M, SNOWLING M.J, SCANLON D.M. Specific reading disability (dyslexia): what have we learned in the past for decades? J Child Psycohol |Psychiatry.45(1): 2-40. 2004. 
Anexo - Ficha de anotação do Teste de Nomeação de Figuras.

\section{Teste de Nomeação (Ferreira, Nalini \& Pasquali, 2011) Versão Experimental}

Nome: Idade: Data:

Apresentar a figura (20'de latência) Anotar a resposta literal espontânea/ Oferecer a pista semântica, em caso de fracasso. /Anotar a resposta literal/ Em caso de fracasso oferecer a pista fonética/ Anotar a resposta literal. Interromper com 10 erros consecutivos.

\begin{tabular}{|c|c|c|c|c|c|}
\hline Figura & Resposta & Pista Semântica & Resposta & Pista Fon. & $P t$ \\
\hline 1) Sol & & Faz parte da Natureza & & & \\
\hline 2) Bicicleta & & Meio de Transporte & & & \\
\hline 3) Nuvem & & Faz parte da Natureza & & & \\
\hline 4) Tesoura & & Ferramenta para cortar & & & \\
\hline 5) Pipoca & & Alimento & & & \\
\hline 6) Cadeado & & Usado como fechadura & & & \\
\hline 7) Serrote & & Ferramenta & & & \\
\hline 8) Folha & & Faz parte da Natureza & & & \\
\hline 9) Faca & & Objeto para cortar & & & \\
\hline 10)Cenoura & & Vegetal & & & \\
\hline 11) Óculos & & Usado como lente & & & \\
\hline 12) Limão & & Fruta & & & \\
\hline 13) Pincel & & Utensílio para pintar & & & \\
\hline 14) Lápis & & Usado para escrever & & & \\
\hline 15) Flor & & Vegetal & & & \\
\hline 16) Abóbora & & Vegetal & & & \\
\hline 17) Escada & & Meio de subir e descer & & & \\
\hline 18)Abacaxi & & Fruta & & & \\
\hline 19) Abajur & & $\begin{array}{c}\text { Usado como acessório } \\
\text { de iluminação }\end{array}$ & & & \\
\hline 20) Milho & & Vegetal & & & \\
\hline 21) Interruptor & & $\begin{array}{l}\text { Acessório para } \\
\text { iluminação }\end{array}$ & & & \\
\hline 22) Alho & & Vegetal & & & \\
\hline 23) Avião & & Meio de Transporte & & & \\
\hline 24) Uva & & Fruta & & & \\
\hline 25) Violão & & Inst.musical & & & \\
\hline 26) Maçã & & Fruta & & & \\
\hline 27) Tambor & & Inst. Musical & & & \\
\hline 28)Melancia & & Fruta & & & \\
\hline 29) Igreja & & Lugar de oração & & & \\
\hline 30) Zebra & & Animal & & & \\
\hline 31) Gravata & & Vestuário & & & \\
\hline 32) Peixe & & Animal & & & \\
\hline 33) Âncora & & Usado como apoio & & & \\
\hline 34)Galo & & Animal & & & \\
\hline 35) Tótem & & Símbolo Sagrado & & & \\
\hline 36) Girafa & & Animal & & & \\
\hline 37) Pretzel & & Alimento & & & \\
\hline 38) Vaca & & Animal & & & \\
\hline 39) Tomada & & $\begin{array}{l}\text { Dispositivo para captar } \\
\text { corrente elétrica }\end{array}$ & & & \\
\hline 40) Elefante & & Animal & & & \\
\hline 41) Laço & & Usado para amarrar & & & \\
\hline 42) Leão & & Animal & & & \\
\hline 43) Cabide & & Usado para colocar & & & \\
\hline
\end{tabular}




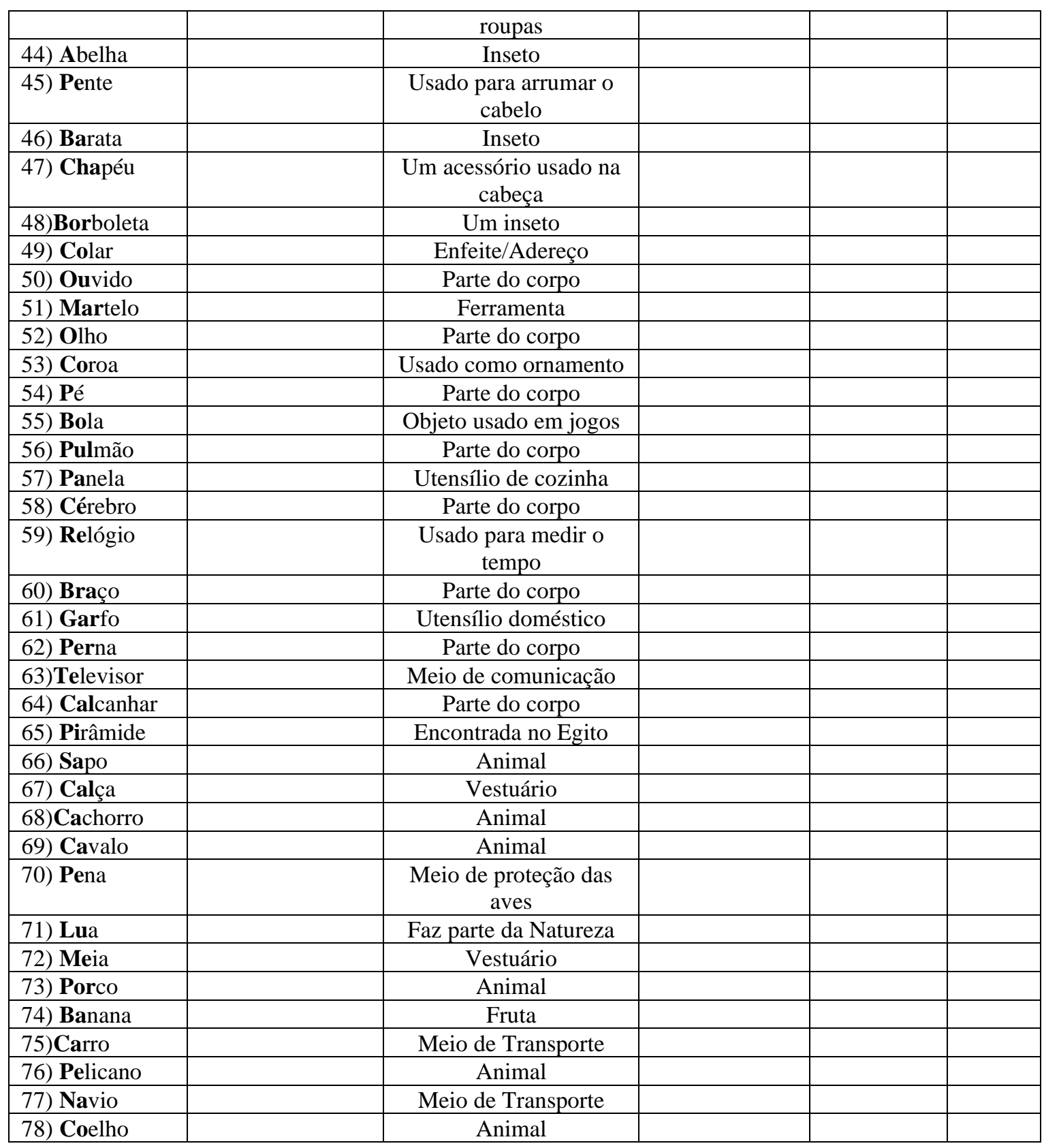

Total de pontos: Acerto resposta espontânea + pista semântica

\begin{tabular}{|c|c|c|c|}
\hline \multicolumn{4}{|c|}{ Respostas Corretas espontâneas } \\
\hline \multicolumn{4}{|c|}{ Respostas } \\
\hline \multicolumn{4}{|c|}{ Corretas após pista Semântica } \\
\hline \multicolumn{4}{|c|}{$\sum$ de espontâneas + Pista Semântica } \\
\hline \multicolumn{4}{|c|}{ Análise Qualitativa } \\
\hline $\begin{array}{c}\text { Circunlóquio } \\
\text { Presente/Ausente }\end{array}$ & $\begin{array}{c}\text { Confabulação } \\
\text { Visual } \\
\text { Ausente/Presente }\end{array}$ & $\begin{array}{c}\text { Neologismo } \\
\text { Presente/Ausente }\end{array}$ & Categoria mais prejudicada \\
\hline
\end{tabular}

